\title{
Civil and Ethnic Identity of Population Bordering Regions of Russia
}

\author{
Svetlana Maximova, Oksana Noyanzina, Daria Omelchenko, Maksim Maximov, and Maksim Krysin \\ Altai State University, Russia
}

\begin{abstract}
Characteristics of actual condition of civil and ethnic identity of Russian population are given in the article. It is marked out, that the tendency to the actualization of ethnic identity among residents of bordering territories occurs. The given process is caused by wide spectrum of factors of global, country and regional level. Authors conclude that contemporary global processes, peculiarities of social-economic condition and political elite actions promote to the strengthening of ethnic aspects on Russian's identity. All these creates threats to national and social security. It is pointed out, that the formation of the "all-Russian" civil identity, providing consolidation of population basing on common values and priorities, is the necessary condition of preserving sovereignty and totality of the country. At the same time, a low level of institutional trust and social-economic problems led to the strengthening of ethnic identification as the most effective instrument of social adaptation.
\end{abstract}

Keywords: ethnic identity, civil identity, factors of forming of identity in bordering region

\section{Introduction}

Russia is poly-ethnic, poly-religious, poly-cultural society and one of the largest poly-ethnic states in the world. By data of All-Russian general census of 2010, number of resident population is 142.9 million of people (74\% - urban population, 26\% - rural population). Russians are the most part of resident population, but the Census fixed 194 ethnic communities in Russia. During period of 2002-2010, size Russian of population reduced from 115.9 million of people to 111.0 million, or $4.2 \%$. However, in related terms, part of Russians increased among people, who indicated nationality (from $80.6 \%$ up to $80.9 \%$ ).

Specifics of political and social development of contemporary Russia are activation of processes of ethnic differentiation. Many researches mark out, that ethnic and regional identity of Russians nowadays dominate and determine character of social-political relations more than all-civil identity $[1,3]$. Such situation caused by complicated complex of factors of global, all-Russian and regional level.

Manifestations of globalization, such as institutionalization of international policy structures, integration of national economics, spread of unified mass culture, enforcement of migration streams inevitably lead to destroy of territorial and social-cultural borders, former markers of ethnic identity. Actualization of 'local' ethnic and religious self-consciousness of population became the appropriate consequence in this case. Together with understanding of problem of 'smearing' of own ethnos, ethnic communities try to preserve cultural originality, traditional live style and social practices with help of territorial separation, back to traditional ways of economy, strengthening of positions of native language and law restrictions [4].

Problem of forming of ethnic and civil identity of population obtains a special sharpness in border regions of Russia, which are at the 'joint' of geographic, political, economic, ethnic-cultural and confessional borders. As N. Mezhevitch pointed out, borders form territorial communities. They are necessary 'pivots' for selfidentification of bordering population [5]. V. Kolosov also marks a high contrast in social notions ('we' and 'they' contradictory), characterizing border territories, cultural, ethnic and linguistic areas [6-8]. In particular, it is the reason why several border ethnos are so conflict. A great significance belongs to the evidence if 'ethnic' borders: the more actual self-identification with own ethnic group, the higher risk of interethnic contradictory [9]. Considerable role in determination of interethnic and international interaction at the border plays history of interactions of neighboring nations and ethnos in the past [10]. It is significant, that characteristic trait of ethnic consciousness of people of number Russian regions is deferred reaction on national policy of Soviet state, promoted to emergence of ethnocracy regimes in country. Nowadays, in number of Russian regions, ethnicity is latent base for unequal access of subjects or groups to some power or administrative resources [11]. Thus, we should consider that form the moment of the end of civil war up to the middle of 1950s, practice of repressive 
policy such as internal deportation of certain ethnic groups (so as social-economic deportations) became spread in the USSR. Forced deportation (in Siberia and the Middle Asia, dominantly) covered more than 60 ethnic groups [12]. Forming of complex of 'ethnic insult' and development of radical nationalist movements as among deported nations as among population of regions, receiving forced alien ethnic migrants became the appropriate consequence too. Wide proclamations about ethnic repressions started in the beginning of 1990s. Thus, representatives of suffered from Stalin's policy nations, for a long time lived in conditions of official negation and suppression of the given facts.

But close interaction between different ethnic groups is able to create psychological tension by itself [13]. Interethnic communication could be problem because of certain cultural differences at the level of the world picture, hierarchy of values and norms and behavioral patterns.

It is also significant that population of birder territories is poly ethnic, including the reason of active migration streams. In Russia is the most considerable labor (including illegal) migration of the Commonwealth of Independent States and China citizens [14-15]. Researches mark, that nowadays security of Russian borders is provided by economic collaboration between Russia and its 'neighbors' and latent political 'agreements', providing, for example, economic help in return of stability in border regions of contiguous states [16]. A number of realized researches testify the fact of economic contradictory between ethnic groups in border regions [17-18]. Migration to alien country is stress. So it causes for high level of ethnic consolidation of migrants. Thus, S. Ryazantcev considers, that ethnic consolidation is 'unique internal social immunity, that emerges in conditions than ethnic group became ethnic minority in a result of migration' [19]. Processes of ethnic consolidation are especially evident in small compact grouos of alien ethnic migrants.

At the same time, we see rather considerable change in ethnic composition of population in border regions of Russia. Basing on the All-Russian general census of 2010 data, L. Kristalinsky revealed a tendency of constant decrease of Russian population in border regions [20]. In his opinion, such process should have 'rather evident influence on opportunity of realization of interests of Russian national security in border areas' [20]. It is conditioned by the fact that Russian population divides values of all-Russian civil identity, despite representatives of not title ethnos in Russia. According to L. Drobizheva, 'Russians had fast reconstruction of state-civil identity [after the USSR's break-up] in comparison with other Russian nations, and their identity became more evident' [21]. The reason is: Russian populations are more disposed to identify themselves with state political institutes, self-determine through the belonging to the Russian state [22]. But state, all-Russian identity is less considerable for population because of remoteness from political center and poly ethnic character of border territories of country, on the other side, ethnic identity is closely connected with the place of living [23]. Researches by V. Avksentyev and B. Aksyumov showed, in particular, dominating role of ethnic identity on border regions of Russian South [1]. Thus, border regions are characteristic by evident risks of social-political instability because of high latent ethnic conflicts.

\section{Details Experimental}

\subsection{Organization of research and methodology}

Analysis of characteristics of civil and ethnic identity realized basing on data of sociological research 'Civil and ethnic identity in the system of preservation of social security of population of border regions of Russian Federation' (2015), Sampling consisted of 2400 respondents in six regions of Russia (46\% of men and 54\% of women, $27.4 \%$ of respondents were at the age of 15-29 years, $37.0 \%$ - 30-49 years, $35.6 \%$ - from 56 years and older).

To evaluate condition of observed phenomenon we used following indexes:

Level of identification with Russian citizens, citizens of own region, settlement, representatives of own confession, nationality, profession and etc. (from 1 - 'in considerable extent' up to 4 'do not feel identification');

Indexes of level of identification with ethnic groups, civil and religious communities, counted basing evaluation of 18 positions (from 1 - 'absolutely disagree' up to 5 'absolutely agree');

Identification with one or several ethnic group;

Relation to alien ethnos;

Relation to national policy of the state; 
Evaluation of level of interethnic tension in country and region;

Evaluation of evidence of characteristics of ethnic sphere basing on scaling from 1 to 10

To determine public opinion about condition of interethnic sphere in region, we realize factor analysis. In result we formed basing on a raw of parameters 3 variables and followed up correlation between socialdemographic characteristics of respondents with their evaluation of relations between ethnic groups.

We also realize regression analysis, evaluating correlation between civil and ethnic identity and level of religious identity and social-demographic characteristics of respondents.

\section{Results and Discussion}

One of the most common indexes of civil identity is the self-identification with country citizens. By data of the research, 96\% of respondents in border regions consider themselves as Russians. By this, $80.3 \%$ of respondents feel considerable proximity with community of Russian citizens and $15.6 \%$ - feel a small proximity. In sum we have the same 96\%. Regional and local identity is also wide expressed: parts of respondents who consider themselves close to region's (94.9\%) and own city or village citizens (95.3\%) are high. However, index of local identity is higher for rural countrymen: considerable proximity with fellow villages feel $81.4 \%$ of respondents, than urban countrymen feel proximity with city community in $73.7 \%$ cases $\left(\chi^{2}, p<0,05\right)$.

We found verification for hypothesis about priority of civil identity over ethnic one in social identity of Russians. Considerable proximity with representatives of own ethnos mark $66.3 \%$ of respondents that is $14 \%$ less with proximity with all-Russian community. The less part of respondents associate themselves with persons of their generation (61.3\%), profession $(49.4 \%)$ and faith $(42.4 \%)$. Thus, civil identity is the more often manifested in Russia. The ethnic one has an important meaning, but inferior to civil identity.

To determine the correlation between civil, ethnic and religious identity of respondents, we suggested statements about identification with these or those communities. By counting the median values for indexes $(1-$ absolute disagreement, 5 - absolute agreement with statements, positively characterizing community and affiliation to it), we obtained the following: for ethnic identity -4.01 , for civil identity -4.27 and religious identity -3.48 points. Level of agreement with some statements also testifies about less value of ethnic identity ('absolutely agree' and 'tend to agree' answers): $87 \%$ of respondents feel themselves as a part of Russian culture and $78.3 \%$ - part of ethnic culture. 63.8\% happy to be part of ethnic group, and to be Russians - 80.1\%. Part of respondents in total sampling $(52.4 \%)$ and $70.7 \%$ among those who follow a certain religion consider religious identification as important part of themselves.

Let us consider characteristics of ethnic identity in details. We asked citizens of bordering regions with the question: "What is your ethnos (nationality)?". In result, $87 \%$ determined themselves as Russians (92.3\% by data of the All-Russian Population Census), 5.4\% marked different ethnic groups, and 5.3\% characterized themselves as Russians and representatives of other ethnic groups simultaneously (Ukrainians, Byelorussians, Germans, Polish, Kazakhs, Tatars and etc.) and by this they referred from two to four ethnic groups. For $2.2 \%$ of respondents ethnic identity became identical to civil one ${ }^{\wedge}$ they called themselves as Russians or Russian citizens.

It is very important to understand the base for ethnic identity. The often reason for ethnic self-determination is use of native language (as $75.3 \%$ of respondents marked), further follow: parent's nationality (64.1\%), affiliation to national culture $(54.7 \%)$ and living at native territory - motherland of ethnic group (42\%).

Considerable characteristic of ethnic identity is relation to other ethnic groups. Thus, $36.3 \%$ of respondents feel positive in relation to representatives of 'alien' ethnos, $51.4 \%$ - neutral and $7.8 \%$ - negative feelings. Ruther often understand persons of 'alien' ethnos as 'enemies' $2 \%$ of respondents, often $-8.7 \%$ of respondents, that is lower than by results of all-Russia survey by Levada center in October, 2013 (very often understand persons of 'alien' ethnos as 'enemies' $6 \%$ of Russians, often $-14 \%$ of respondents). An antipathy to representatives of certain ethnos and nations was explained by unwillingness to follow Russian traditions and rules of behavior (25.3\%) and possible threat of terrorism (23.7\%). Meanwhile respondents rarely spoke about hostility of 'alien' ethnos towards themselves. In total, the most part of respondents $(63 \%)$ characterize relations between people of different ethnos as normal and conflict-free, $13.9 \%$ evaluate such relations as friendly, and $8.1 \%$ - as tense, conflict and 'explosive'. 
Friendship to representatives of other ethnos in bordering regions of Russia was evaluates higher above the average: average evaluation of the variable in total sampling represents 5.73 points (diapason of possible values from 1 to 10). National policy of regions also was evaluated as rather favorable (average meaning 5.15). Respondents disagree with hypothesis about interethnic tension: average evaluation 4.05 points.

Factor values were divided into four groups of percentiles, than we test a correlation between constructed variables with social-demographic characteristics. As a result, correlations with age and ethnic parameters of respondents became significant. The younger groups of respondents characterized by high evaluation of national policy of country: after division for three age groups, respondents at the group of 15-29 years gave the highest evaluations, the lowest evaluations gave respondents at the group of 50-75 years $\left(\chi^{2}, \mathrm{p}<0,05\right)$. Especially significant to mark the fact of higher evaluation of national policy by Russians, more than other nationalities. Meanwhile Russians often marked indexes of interethnic tension and friendship towards 'alien' ethnos $\left(\chi^{2}\right.$, $\mathrm{p}<0,05)$.

Let us see characteristics of civil identity of citizens of bordering regions of Russia. To be citizen of the state - is to be the patriot and to love Russia for $52.4 \%$ of respondents; is to comply with the laws and respect the Constitution for $52.2 \%$ of respondents; is to understand civic duty and civic conscience for $34.1 \%$ of respondents; is to have rights and use them for $32.3 \%$ of respondents. Thus, we fixed the presence of all general components of civil identity, mentioned above (patriotism, civility and understanding of state affiliation).

One of the most significant components of civil identity is patriotism, as results of our research testify. $89.5 \%$ of respondents fell proud for the country. The most 'popular' reasons of proud - victory in the Great Patriotic War (60.3\%), prestige of the Russia in the world (38\%), great Russian artists (30.3\%) and President Vladimir Putin (26.6\%).

A feeling of shame for the country expressed $57.3 \%$ of respondents even once. The most 'popular' reason here is the low level of life, low level of salaries, unemployment and poverty (57.3\%). Further follows corruption and bureaucracy (41.2\%), decline of industry, agriculture, economy in whole (31.5\%); alcohol and drug use $(26.5 \%)$. The less popular are reasons, concerned with internal policy. It indirectly indicates for support of modern political course.

We used regression analysis to evaluate level and importance of correlation of civil and ethnic identity with different factors. Index of religious identity and social-demographic characteristics acted as predicates. We revealed significant correlation with dependent variables for predicates - nationality, marital status, level of education and type of settlement (Table 1).

TABLE 1: Regression models of prediction of civil and ethnic identity

\begin{tabular}{lcc}
\hline \hline Predictors & Civil identity & $\begin{array}{c}\text { Ethnic } \\
\text { identity }\end{array}$ \\
\hline Nationality & $\mathbf{- 0 , 1 0 3}{ }^{*}$ & $-\mathbf{0 , 1 7 0}$ \\
Marital status & $-0,005$ & $-0,003$ \\
Material condition & 0,021 & 0,014 \\
Level of education & $-0,027$ & 0,021 \\
Type of settlement & $\mathbf{- 0 , 0 9 3}^{*}$ & $-0,01$ \\
Religious identity & $\mathbf{0 , 4 9 1}^{*}$ & $\mathbf{0 , 4 5 2}$ \\
Total R ${ }^{2}(\%)$ & 26,7 & 24,2 \\
\hline \hline Values in sells represent standardized coefficients $(\beta)$ of final model. ${ }^{*} \mathrm{p}<0,01$.
\end{tabular}

In whole, presented factors made considerable input into explained dispersion of dependent variables (for civil identity $R^{2}=0,267$, for ethnic identity $\left.R^{2}=0,242\right)$. Determinative influence at levels as of civil $(\beta=0,491$, $\mathrm{p}<0,01)$, as of ethnic identify $(\beta=0,452, \mathrm{p}<0,01)$ in constructed models belonged to the level of religious identity. The given index was built basing on results of summarizing of strength of religious - self-identification with representatives of certain confession, striving to confess and follow the rules of confession. Such level of correlation gives evidence of higher tendency of religious respondents to feel proximity with other referent communities - as state-civil group as the ethnic one.

Nationality had the most considerable influence for dependent variable among other predictors (for civil identity $\beta=-0,103, p<0,01$, for ethnic identity $\beta=-0,170, p<0,01)$. Taking into consideration type of coding for nationality (Russians decoded as ' 1 ', other nationalities - as ' 2 '), negative values of coefficients speak about the 
most extent of civil and ethnic identity among Russians. Type of settlement had minor influence on civil identity: the bigger the settlement the more negative value for the given variable.

Research results verify high level of civil identity of citizens of border region, its priority over ethnic identify, expressed in wide spread associations with citizens of Russia than with certain ethnos and ethnic selfdetermination as "Russians".

Analysis of indexes of ethnic identity showed absence of evident clear identification with one of regional ethnic groups among border region citizens. We fixed cases of simultaneous identification as with Russians as with representatives of other nationalities, that can testify competitiveness between factors of origin and cultural identification in self-identification.

Characteristic of sphere of interethnic relations became important research result. We fix law level of interethnic tension and conflicts, considerable extent of loyalty towards alien ethnic groups and moderate revelation of ethnic separatism. Correlation of indexes of tension in border regions and Russia in whole let us to conclude on more favorable condition in border regions. In particular, it could be connected with rather homogeneous ethnic composition. But we fixed a certain level of rejection of 'alien' ethnos.

Research established correlation between extent of revelation of civil and ethnic identity and strength of religiousness.

Thus, contemporary situation of forming of civil and ethnic identity of population of border regions of Russia is a result of influence of complicated complex of factors, acting at global, country and regional levels. External global threats, enforcement of migration streams, myths about common historical past, political rhetoric and social-economic problems such as stagnation of economy, low level of life and unemployment promote to the 'ethnithication' of consciousness of citizens of border regions. Civil identity in contemporary Russia acts as an object of political constructing. Different resources of political, economic, information and cultural influence are used in this process. But due to the deficit of institutional trust ethnic identity often becomes the base for consolidation of citizens of border regions. Influence of political 'center' is rather weak on the border, so constant clash of border population with 'alien' cultural attitudes and behavioral patterns actualize the need in ethnic self-categorization. Solution of this problem is possible with condition of provision of law, economic and social protection of population in border Russian regions.

\section{Acknowledgements}

Article prepared under support of the Ministry of education and science of Russian Federation to the Altai State University. Project code 1475 'Civil and ethnic identity in the system of preservation of social security of population of border regions of Russian Federation'.

\section{References}

[1] V. Avksentyev, B. Aksymov, "Briefcase of identities of youth in South of Russian in conditions of civilization choice", Socis, 2010, vol. 12.

[2] E. Eryomina, "Notion of regional identity and specifics of its forming in contemporary Russia", Social-Humanitarian Knowledge, 2012, vol 5.

[3] N. Ismagilov, "Problem of regional identity in Russian social-cultural area", Geography and natural resources, 2009, vol. 3 .

[4] D. Held, et. al., "Global transformations: Politics, Economics and Culture", 2004.

[5] N. Mezhevitch, "Russians in Priangarye: from consortia to convixia" [Online] //http://www.levgumilev.spbu.ru/node/184.

[6] V. Kolosov, "Theoretical lymology: new approaches. International processes", 2003, vol. 3.

[7] D. Omelchenko, G. Maximova, et al, "Patriotic identity and nationalist views of the youth: two borders of one reality", All-Russian scientific-practice conference "Positive experience of regulation of ethnic-social and ethnic-cultural processes in Russian regions" Bulletin, 2014, 508 ps.

[8] S. Maximova, G. Avdeeva, et. al, 'Image of 'alien' as structural components of national identity: constructivist paradigm", Altai State University News, 2014, vol. 2(82). 
[9] N. Lebedeva, A. Tatarko, "Theoretical-methodological approach to the study of tolerance in poly cultural regions of Russia", Institute of ethnology and anthropology of Russian Academy of Sciences, 2005.

[10] V. Kolosov, "Phenomenon of state border", Russian-Ukrainian border; twenty years of divided unity, 2011.

[11] V. Tishkov, E. Kisriyev, "Multiple identities between theory and practice (Dagestan example)", Ethnographic Review, 2007, vol. 5.

[12] A. Tkachenko, "History of deportation of Russian peoples", Russian demographic Journal, 2002, vol. 1.

[13] G. Soldatova, "Psychology of interethnic tension", 1998.

[14] K. Dubovitskaya, V. Gordeev, "External migration as a factor of dynamics of competitiveness at labor market in Russia", Theoretical economics, 2014, vol. 3.

[15] Zh. Zayonchkovskaya, "Transit migration in Commonwelf of Independent States: comparative perspectives", Transit migration and transit countries. Theory, practice and policy of regulating, 2009, $392 \mathrm{ps.}$

[16] I. Ivakhnyuk, R. Daurov, "Illegal migration and security of Russia: threats, challenges, risks", Migration and national security, 2003, vol. 11.

[17] S. Maximova, et. al, "Migration processes and social-economic security pf border regions of Russia", Altai Agrarian State University Bulletin, 2013, vol. 11.

[18] N. Goncharova, et. al, "Illegal labor migration as a risk of social exclusion at Altai labor market: methodology and methodic of research", Altai Science Bulletin, 2013, vol. 1.

[19] S. Ryazantsev, "Ethnic business as a form of migrant's adaptation", Social sciences and modernity, 2000, vol. 1.

[20] L. Kristalinsky, "Border region of Russia: contemporary peculiarities and dynamics of change of ethnic composition" [Online] http://vestnik.pags.ru/vestnik/ archive/New\%20Folder/ Kristalinsky.pdf.

[21] L. Drobizheva, "Indentity and ethnic attitudes of Russians in native and alien ethnic area", Sociological research, 2010, vol. 12.

[22] L. Gudkov, "Russian national consciousness: potential and types of consolidation", "Where the Russia goes?", 1994.

[23] "Methodic of ethnography study of border area", In Social-economic geography: history, theory, methods, practice, 2011. 